\title{
As Primeiras Universidades Brasileiras
}

\author{
Vamireh Chacon
}

Professor universitário (UFPe); escritor

\section{A primeira tentativa}

Desde, pelo menos, a Assembléia Constituinte do Império, em 1823, que foi tentada a instalação das primeiras universidades no Brasil. Antes, podem ter existido sonhos e projetos, mas só naquela ocasião se tomaram providências concretas, embora frustradas, no sentido de realizar uma grande aspiração brasileira.

Spencer Vampré ${ }^{1}$ e Clóvis Beviláqua ${ }^{2}$ são dos primeiros que deram notícia do esforço, porém de maneira breve, em função das faculdades de Direito que restaram da intenção inicial.

Propomo-nos aqui a analisar o início de um debate pleno de lições, ainda hoje válidas, a respeito do destino da Universidade em nosso País.

Era o Alvorecer da Independência.

O Deputado José Feliciano Fernandes Pinheiro, depois Visconde de São Leopoldo, representante do Rio Grande do Sul, levantou sua voz para oferecer a seguinte "Indicação", conforme se chamava na linguagem da época:

"Proponho que no Império do Brasil se crêe quanto antes uma universidade pelo menos, para assento da qual parece dever Ser preferida a cidade de São Paulo, pelas vantagens naturaes, e razões de conveniencia geral. 
Que na faculdade de direito civil, que será sem dúvida uma das que comporá a nova universidade, em vez de multiplicadas cadeiras de direito romano, se substituão duas, uma de direito público constitucional, outra de economia politica. Paço da assembléia, 12 de junho de $1823^{n}$. $^{3}$

Por este documento logo se constata a preocupação prática do legislador: ele previa um destaque para a Faculdade de Direito que prepararia juristas, administradores públicos e estadistas, para isto necessitando de conhecimentos constitucionais e econômicos.

O debate alastrou-se, menos quanto à urgência da instituição, que a respeito da sua localização. O Deputado Carvalho Melo, lembrando ser o Brasil "um paiz tão dilatado, tão cheio de riquezas, e que com o andar dos tempos crescerá em povoação, ha mister que nelle se estabeleção duas universidades, uma na cidade de S. Paulo e outra em Pernambuco". Argumentava facilidades de transporte para os dois locais "clima sadio, abundante em viveres", porém concluia : "comtudo, no estado actual não se póde nem devem estabelecer mais, porque nem a povoação é tanta, que exija maior numero de universidades, nem a falta de mestres e de cabedaes para as suas despezas permite maior numero".

O Deputado pernambucano Muniz Tavares, herói das jornadas de 1817. também preocupado com as implicações práticas. concordou com as universidades, mas insistiu que se fundassem. "desde já", um "curso juridico" em São Paulo e outro em Olinda.

Aquela exigência operacional ganharia terreno na palavra do Deputado Almeida e Albuquerque, de Minas Gerais, discordando da Universidade e concordando apenas com uma Faculdade de Direito em São Paulo, por motivos bem materiais e imediatos: "Que dos fundos para ella? Que dos mestres? Que das razões que ha para ser alli que vá estudar o curso juridico ?" Animado pelas dúvidas, terminou chegando à conclusão: "E que pressa ha de se abrir um curso de direito primeiro que o de outras sciencias mais uteis, e mais necessárias ?"

A discussão desdobrava-se. Tornando-se incontrolável.

O experiente baiano, Visconde de Cairu, outro Deputado, vendo o entusiasmo esfriar, preferiu salvar o mínimo para sua província : "Portanto não voto, nem posso votan por fórma ne. 
nhuma por um collegio singular em S. Paulo, se acaso o querem ahi então estabeleça-se também na Bahia, Pernambuco, e em todas aquellas provincias onde se exigem subsidios para estabelecimentos litterarios; e se for vencido que uma só provincia tenha esse collegio, então a commissão deve propôr que se abra na Bahia". Argumenta : "O collegio deve estabelecer-se no local que offerecer as melhores commodidades ao maior número dos nossos concidadãos, e por isso nenhum outro lugar é mais adequado do que a provincia da Bahia".

Diante disto, o Deputado mineiro Antônio Gonçalves Gomide, após um prólogo rebuscadamente iluminista ("A instrucção publica, e diffusão das luzes é o primeiro dever dos governos. Todas as virtudes civicas e moraes das nações se desenvolvem na razão de suas luzes"), propôs uma posição intermediária, conciliacão óbvia: que a Universidade ficasse na Corte, em plena cidade do Rio de Janeiro. Alegava que Oxford surgira quando capital da Inglaterra do Rel Alfredo "e se acha só a duas léguas de Londres". que "Edimburgo é também universidade marítima. e foi fundada quando era côrte dos reis da Escócia. As côrtes de Paris, Vienna, Berlim, Petersbourgo (sic), têm universidades. $\mathrm{Na}$ America do Norte a primeira universidade foi na sua metrópole Philadelphia". Idem no México etc. E levou sua argumentação ao ponto de pretender que "Talvez Evora e Coimbra, por serem universidades no interior de Portugal, pouco contribuirão para o progresso do espírito humano". Ao contrário de Lisboa, onde o ambiente intelectual seria muito mais propício. Lembrava que, para semente de uma universidade, no Rio,
"Vê-se já o edifício levantado, bem que ainda em miniatura, com aulas das sciencias maiores, da academia da marinha, medicina, com bibliotheca, e typographia publica, jardim botanico e de plan. tas exoticas e museu". Além dos conventos e Seminário, onde "se ensinão theologia, instituições economicas etc": "só faltão os estudos de direito para um curso juridico, que o thesouro póde Pagar sem grave encargo. Eis pois já uma universidade quase formada".

Era um raciccínio objetivo, realista. Dom João VI criara instituições culturais germinativas em Universidade. Estava montado 0 início da infra-estrutura. "Ao contrario, nas outras provincias, excepto a Bahia, é preciso crear quasi tudo". E, frise-se, não ser Gomide nem carioca, nem fluminense; representava, já o dissemos, Minas Gerais. 
O orador concluiu com uma advertência descuidada pelos sucessores na tribuna do Parlamento do seu tempo e da Pedagogia em tempos seguintes: "A que proposito, precipitando-se as épocas dos melhoramentos, se tenta multiplicar universidades, para haver superambundância de doutores desproporcionados aos empregos necessarios do estado, o que é uma das causas, porque actualmente a vaidade e ambição tanto accusão aos governos ?"

Pois, Pereira da Cunha, Deputado pelo Rio de Janeiro e futuro Marquês de Inhambupe, preferiu tudo tumultuar na sessão seguinte, apresentando as seguintes emendas :

"Ao § 1.. Haverá duas universidades, uma na provincia do Maranhão, no lugar que mais convier por sua localidade, e circumstancias, e outra na provincia da Bahia, no sitio de Belém. distrito da villa da Cachoeira, e assim mais um collegio de sciencias naturaes na provincia de S. Paulo, e outro na cidade de Maria. na provincia de Minas Geraes, e finalmente um collegio da faculdade de leis, e de philosofia na cidade de Olinda, aonde haverá igualmente uma cadeira do primeiro anno mathematico". Entrementes, "se dará princípio á fundação da universidade da Bahia logo que se proporcionem os mestres e professores para exercitarem o magistério assim nas sciencias exactas, como nas positivas, artes e bellas letras, servindo de norma para sua instalação os estatutos da universidade de Coimbra", com as devidas modificações, "contribuindo o cofre da mesma provincia com as despezas necessárias para tão util estabelecimento" (ao § 4..$^{\circ}$. $E$, "Ao $\S 5 .^{\circ}$. O governo nomeará um reitor, ou inspetor da mes. ma universidade, que reuna em si as distinctas qualidades que exigem um tão importante lugar. Paço da assembléia, 27 de agosto de $1823^{\prime \prime}$.

Habituado aos debates e à administração pública, Cairu percebeu a iminência do naufrágio e sugeriu, com malícia: "Eu estou pela opinião do Sr. Pereira da Cunha para que se estabeleça uma universidade no Maranhão, e outra na Bahia, e também voto por uma terceira em S. Paulo; mas isto para o futuro; para agora sou de parecer que se funde uma na Bahia e ficaremos já bem servidos". "Voto portanto que se funde já uma universidade na Bahia. e que para o futuro se trate de estabelecr outras no Maranhão e em S. Paulo". Como se não faltasse mais nada, na confusão geral, o Deputado mineiro Teixeira de Gouveia, por sarcasmo ou para encerrar o debate, apresentou mais uma emenda : "Proponho que a haver uma unica universidade no sul que esta se estabeleça na cidade de Mariana..." ${ }^{4}$ 
Cansados, os parlamentares preferiram passar adiante e discutir o projeto, mais urgente, da Constituição. Porém, depois, logo a tentação universitária voltou à tona.

Gomide, Teixeira de Gouveia, Pereira da Cunha e mais Araújo Lima (Pernambuco, futuro Marquês de Olinda) e Arouche Rendon (São Paulo) retornaram à cargo, com outro projeto de lei, nos seguintes termos:

"Art. 1. . Haverão (sic) duas universidades, uma na cidade de S. Paulo, e outra na de Olinda: nas quaes se ensinarăo todas as sciencias e bellas letras.

Art. 2. Começará o anno lectivo em 1824 depois das ferias da Paschoa da Ressurreição.

Art. $3 .^{\circ}$. Fundar-se-hão universidades semelhantes nas capitanias das outras provincias do Imperio do Brazil, quando forem requeridas pelos respectivos povos, e governos locaes, que designarem e segurarem os fundos, e creditos de cada uma, necessarios ao estabelecimento, e independentes da sua estabelecida renda publica".

\section{Era a conclliação.}

A teimosia de Cairu viu-se contrabalançada, aqui, pelo bom senso e prestígio de Vergueiro (São Paulo), demonstrando-lhe que a lei não excluia, e sim admitia incluir quem pudesse habilitar-se: "O Ric de Janeiro já tem bastantes (sic) privilégios, não se lhe deve conceder mais; basta a independência em que está, ao mesmo passo que as outras têm de vir aqui procurar os seus recursos". "Eu conformo-me muito com esta proposição e ainda que pareça que ella implica com a designação fixa dos lugares das duas não é assim; escolheu-se S. Paulo e Olinda, como os dous pontos mais proprios; mas cada uma póde estabelecer a universidade se quizer, e tiver com que; deve haver ampla liberdade para a propagação das luzes; e assim como não prohibismos escolas particulares, também nã́o devemos prohibir estes estabelecimentos".

\section{O Ufanismo podia soltar as rédeas.}

Outro Deputado exultou: "Tempo virá, e já me lisonjeio em prevê-lo, que cada uma das nossas provincias terá universidades e academias. O Pará terá um dia a opulência presente da Russia, o Maranhão a da Alemanha, Pernambuco a da França, a 
Bahia a da Grã-Bretanha, esta (a Corte) a de toda a Itália, S. Paulo a da Hespanha, Santa Catharina será a nossa Irlanda, a parte meridional do Brasil equilibrará só por si os Estados-Unidos do norte do nosso mundo, enquanto Minas, comprehendendo Goyaz e Matto-Grosso, serão tão opulentos como é hoje a Europa toda".

\section{Ao que Antônio Carlos Ribeiro de Andrada Machado (São Paulo) aparteou, irônico : "É muito exagerar!"}

Sem corrigir o orador, impenitente otimista, embora um tanto profético ao dizer, pelo menos: "Resumindo-me digo, que é vista dos progressos indefectiveis de nossa riqueza, não desconfiemos da falta de meios para uma, ou duas, ou três universida. des, e que elles apparecerão, da mesma fórma que têm apparecido espontaneamente e sem coacção para conventos, templos, etc". Prosseguindo na confiança doadora dos que enriqueceriam as nossas universidades, Gomide sugeriu um "Additamento": "Todo o cidadão que fizer para qualquer universidade do Brasil o donativo de oito contos de réis terá o seu retrato na sala academica, e todos os seus descendentes até a quarta geração serão isentos de paqar matriculas". Apesar das advertências de Miguel Calmon du Pin e Almeida (Bahia), futuro Marquês de Abrantes, urqindo que nos limitássemos a faculdades de Direito, dada a escassez de recursos...5 $\mathrm{E}$ a necessidade do treinamento de quadros administrativos e institucionais para o País.

Nada, porém, deteve o entusiasmo universitário dos parlamentares empolgados pelos debates - muitos deles egressos de Coimbra, Montpellier, Edinburgh - de modo que o projeto das duas universidades, uma em São Paulo e outra em Olinda, acabou sancionado em 4 de novembro de 1823 , não sendo contudo nem promulgado pelo Poder Executivo, nem publicado oficialmente, porque, no dia 12 do mesmo mês, Pedro I dissolvia a Assembléía Constituinte.

Recomposto o Poder Legislativo, segundo o alvitre do Imperador, a Universidade foi posta de lado, nas discussões, limitadas às instalações do que chamavam "um curso juridico" e que deveria ficar na Corte, por proposta de Januário da Cunha Barbosa e José Cardoso Pereira de Melo, terminando convertida em dois. nas duas cidades antes previstas, através de projeto-lei do Deputado paulista Francisco de Paula Souza e Melo, em 8 de agosto de 1826. sancionado em 11 de agosto do ano seguinte, por Pedro I e pelo Ministro referendário Visconde de São Leopoldo, ${ }^{6} 0$ 
mesmo José Feliciano Fernandes Pinheiro que iniciara o debate € podia assim rejubilar-se: "Ao tempo deste meu ministerio pertence o acto, que reputo o mais glorioso da minha carreira politica e que penetrou-me do mais intimo jubilo, que póde sentir o homem público no desempenho de suas funções. Refiro-me á installação dos dois cursos juridicos de S. Paulo e Olinda, consagração definitiva da idéia, que eu aventara na Assembléia Constituinte em. a sessão de 14 de junho". ${ }^{7}$

Não houvera bastante clarividência nem daqueles parlamentares iluministas, nem do também paradoxal Imperador liberal-autoritário. Gomide tinha razão : no Rio de Janeiro existiam já “aulas das sciencias maiores", com "a academia da marinha, medicina, com biblioteca, e typographia publica, jardim botanico e de plantas exoticas e museu". "Temos, por assim dizer, bom casco de navio". O que não excluia a idéia de descentralização, criando faculdades de Direito em São Paulo e Olinda/Recife, nem ampliando as faculdades de Medicina, em semente na Bahia e Rio de Janeiro desde 1808.

Por falta de visão, perdeu-se o sonho, esvaído em discusSões que se seguiram na Câmara dos Deputados e no Senado até 1834, quando se continuou tentando a organização da "Universidade do Brasil", que reunisse o ensino superior da Corte e suas respectivas infra-estruturas. incapazes de polarização porque as atribuições do ensino tinham sido divididas entre as províncias (níveis primário e secundário) e governo central (nível superior).

Perdidos no emaranhado, merecíamos a conclusão do Padre A. Alonso SJ, antigo Reitor da Pontifícia Universidade Católica do Rio de Janeiro: “...le peuple brésilien n'avait pas encore attaint la maturité indispensable à l'expansion de la culture universitaire".8

Enquanto inaciano, Alonso poderia relembrar e lamentar o fechamento dos jesuíticos colégios das artes, onde se defenderam teses de Mestrado em Filosofia e Teologia desde o século XVI em Olinda e Salvador, conforme o atesta Serafim Leite SJ. ${ }^{9}$ Colégios dissolvidos pelo Marquês de Pombal, em nome do Iluminismo, que deveria ser propagado pelos oratorianos. Embora, na prática, estes não tivessem forças para a substituição, morrendo a frágil planta nascente. Por mais que fosse acusável de "contrareformista" no vácuo e "barroco ultrapassado", aquele ensino oferecia margens de recuperação, contaminado pelo Espírito do TemPo, não mereçndo a sumária extinção. Em seu lugar, não houve 
continuidade. Também não se pode negar que pouco ou nada adiantou a São Domingos, ao México ou ao Peru terem universidades desde o início da colonização, em pleno século XVI, embebidas dos vícios que contaminariam a nós igualmente, prolongamentos dos mesmos erros. A flexibilidade portuguesa sempre se apresentou maior que a espanhola, no fundo castelhana, hirta e orto. doxa. Com muitc menos tentações heréticas.

\section{A segunda tentativa}

De novo o perfeicionismo e o sectarismo arruinariam a seguinte tentativa de Universidade no Brasil.

Pedro II - apesar do seu humanismo diletante, ou mesmo por causa dele - imaginou possível um organizado ensino superior no Brasil. Afinal de contas o nosso País crescera, e o Imperador, correspondente de sábios, constrangia-se diante da desconfiança do mundo acerca do descompasso entre a evolução material e a evolução intelectual desta parte do Continente.

E, num paradoxo, os positivistas, tão cientificistas, seriam - maior obstáculo para a concretização do plano, em nome de princípios teóricos que parecem ocultar o temor que a Monarquia consolidasse seu prestígio, coroando sua obra com uma Universidade.

Mal começava o debate, logo desabou a tempestade.

Miguel Lemos, "Diretor do Pozitivismo no Brazil" conforme se intitulava, ou Chefe da Igreja Positivista entre nós, segundo o intitulavam, não vacilou em atacar frontalmente a idéia em protesto publicado na Revue Occidentale, em Paris, em $1 .^{\circ}$ de março de 1881. traduzindo ao português no ano seguinte, aparecendo num opúsculo em companhia de artigos de R. Teixeira Mendes. seu Lugar-Tenente, surgidos na imprensa do Rio de Janeiro. pelo segundo.

O primeiro descreve as linhas gerais desenvolvidas, depois,

Partia Lemos do pressuposto "Que o Brazil possúi um número mais que suficiente de escólas superiores para satisfazer às necessidades profissionais, e que a fundação de uma universidade só teria como rezultado estender e dar maiór intensidade às deploráveis pretensões pedantocráticas da nossa burguezia, cujos filhos abandônão as demais profissões, igualmente úteis e honró- 
zas, para só preocupar-se com a aquizição de um diploma qualquér". "Ésta tentativa absurda, que só poderia gerar como rezultado a sistematização da nóssa pedantocracia e o atrofiamento do dezenvolvimento sientifico, que déve assentar em um regímen de completa liberdade espiritual, bastaria por si só para demonstrar a incapacidade política dos nóssos governos".

Convergindo o ataque em Pedro II - pois "a criação ou não criação da Universidade depende escluzivamente, como tudo o mais, da vontade de S. M. o Imperador, é para o seu patriotismo que apelamos em primeiro lugar" - expõe os seguintes argumentos fundamentais, além do enunciado inicialmente :

"1. Q Que as universidades de Estado, depois de têrem sido os fócos da liberdade espiritual, quando o catolicismo tornou-se opressor, tórnarão-se hoje. por sua vêz, instituições decadentes e um dos maióres obstáculos a toda livre tentativa de reorganizaÇão espiritual;

$2^{\circ}$. Que a criação de similhante instituição em nósso país não corresponde a nenhuma necessidade real, mas sómente o patriotismo mal esclarecido de um cérto número de cidadãos que nos arrástão assim a imitar organizações caducas, contra as quais protéstão ha muito tempo todos os espiritos emancipados do vélho mundo".

Em lugar do desperdício de dinheiro com "ésta tentativa retrógrada, que nada justifica", "Que a atividade e os capitais que vão ser assim empregados, contra os interésses do país e em proveito dos parazitas sientíficos, deveríăo ser consagrados à solução do nósso grande e iniludível problema social - a eman. cipação dos escravos, - à educação dos libértos, e à decretação de medidas tendentes a pôr a nóssa legislação em harmonia com os nóssos costumes". ${ }^{10}$ perspectiva.

$\mathrm{O}$ raciocínio pecava pela unilateralidade. $\mathrm{O}$ que invalida sua

Antes de mais nada, por motivos antes ideológicos que filosóficos, os positivistas, agora pela palavra de Teixeira Mendes, alegavam que a Revolução Francesa ("esplozão redentora") suprimira "todas as corporações sientíficas e metafízicas", "inclusive a Academia das Siências". Abrindo caminho para superar os es. tágios teológico e metafísíco da Humanidade (dada a deformação da Ciência, antes de Comte...), rumo à meta positiva (positivista...). 
Porém Napoleão pusera as coisas a perder, entre outros gestos restaurando, fortalecida, a "Universidade de França", pois "não ha Estado político fixo sem uma corporação docente com princípios fixos". E "A difuzão da siência oficial, unida ao patronato do governo, produs o acendente das mediocridades persistentes".

Portanto, acima de tudo, os positivistas queriam desfraldar a bandeira da Liberdade do Pensamento. Embora fossem tão confessionais, até mesmo litúrgicos e sectários. Enquanto os franceses, com Littré à frente, preferiam o Comte da primeira fase, autor do Cours de Philosophie positive, os brasileiros optavam pelo segundo Comte, o do Système de Politique positive, propagado por Laffite, numa negação religiosa do anterior, fundando Igreja e divinizando seu amor platônico por Clotilde de Vaux...

Chegavam a pretender que "só os positivistas pódem ser liberais, porque só eles confião no poder da siência, que funde as inteligências, e no amor social, que unifica os corações, garantindo a órdem e o progresso pelo consentimento e pela convicção dos elementos sociais". "Liberalismo" compatível com a defesa da "Ditadura republicana"...

Em seguida, diziam existir mais urgentes prioridades que a do ensino universitário (previsivelmente, segundo eles, dogmático-teológico ou dogmático-metafísico, por conseqüência desprovido de pesquisas). Entre elas se destacando o problema social brasileiro, definido enquanto divisão entre uma minoria exploradora e uma maioria explorada ("proletariado"), sem, contudo, qualquer explicação a respeito dos modos de exploração, nem multo menos acerca dos caminhos para vencê-los.

Enfim : em vez de sugerirem a fusão ou, no mínimo, coordenação das faculdades de Direito, Medicina, Museus, Observatório Astronômico e outras instituições, propunham a redução dos seus recursos, inclusive os das escolas Militar e da Marinha, além da sumária extinção do Colégio Pedro II e da Escola Normal!!! ! ${ }^{11}$

Faltou-lhes o mínimo de integrada percepção da Cultura, eles que tanto falavam em "Evolução", "Progresso" e até "Dezenvolvimento" na sua arrevesada caligrafia. Neles triunfou o Dogmatismo recusado apenas verbalmente : ou a cosmovisão positivista seria a única aplicada, ou a de ninguém...

Daí sua contínua oposição ao ensino obrigatório (e à própria vacinação obrigatória, por eles alcunhada de "tirania sanitá. 
ria", sic), mesmo após a Proclamação da República, da qual tam. bém Teixeira Mendes se desapontaria, chegando a denunciar: "Antes de tudo. cumpre insistir no contraste entre o ideal republicano, como ele se aprezentou aos promotores da regeneração social e aos seus continuadores até hoje; como ele se oferéce, cada vês mais enérgicamente, à massa proletária; como ele se anunciou com Benjamin Constant a 15 de novembro de $1889 ;$ - e o regímen tîrânico e corrupto, a um tempo retrógrado e revolucionário, que a burguesocracia (sic) dominante, quér no Brazil, quér no Ocidente, tenta instituir por toda a parte". ${ }^{12}$

Os positivistas, em nome da Liberdade do Pensamento, chegaram ao ponto de repelir qualquer fiscalização estatal das escolas particulares ${ }^{13}$, invocando, paradoxalmente, a dogmática opinião de Cumte a respeito ${ }^{14}$ e investindo, com fúria especial, contra Vicente Licínio Cardoso, simpatizante do Positivismo, recebendo a resposta "que uma pessoa que tem vivido e pretende contmuar \& viver apoiada materialmente e prestigiadamente (sic) pelo Governo temporal, caréce das condições de independência moral e mental, para apreciar os ensinos de Augusto Comte. Pois esses ensinos condênão, ao mesmo tempo, a concessão de tal apoio, por parte dos teoristas, enquanto não houver prevalecido socialmente a doutrina que os ditos teoristas prégão". ${ }^{15}$

Sabendo-se, conforme Ivan Lins demonstrou melhor que ninguém até hoje $\mathrm{e}^{16}$, a penetração dos positivistas em todos os setores do ensino superior, surpreende como eles rejeitaram a criação das universidades, mesmo sob o regime republicano, quancio quase chegaram a dominar o seu alvorecer. Ou será que, temerosos das próprias forças, preferiam diluir os adversários ?

Demonstraram, ainda nisto, excepcional falta de visão, perdendo uma grande oportunidade para influenciar, com maior profundidade, a Cultura brasileira. E, na sua obstinação, prejudicaram a si e ao País.

Crescera a infra-estrutura de ensino superior no Brasil, com inevitáveis contradições, típicas do seu pioneirismo, e os positivistas teimavam em ignorá-lo, apesar de nele estarem inseridos, enquanto alunos e professores.

Para ter-se uma idéia da situação do ensino superior, entre nós, nos fins do século XIX, quando já seria possível agrupá-lo em universidades, basta observar a seguinte lista, de instituiçōes 
funcionando, com respectivas datas de inauguração, embora com instalação prolongando-se anos após :

Rio de Janeiro

Faculdade de Medicina .................... 1808

Escola de Engenharia ....................... 1810

Escola de Belas-Artes ................... 1816

Escola de Música ........................... 1848

Escola de Odontologia ..................... 1856

Escola Politécnica .......................... 1874

Salvador

Faculdade de Medicina .................. 1808

Escola de Agronomia ........................ 1877

Escola de Belas-Artes ..................... 1877

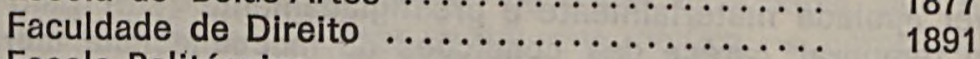

Escola Politécnica ...................... 1897

\section{São Paulo}

Faculdade de Direito .................... 1827

Escola Politécnica ......................... 1893

Escola de Engenharia Mackenzie ............... 1896

Faculdade de Farmácia ................... 1899

Recife

Faculdade de Direito (antes em Olinda) ...... 1827

Escola de Engenharia ..................... 1895

\section{Minas Gerais}

Escola de Minas de Ouro Preto ............ 1876

Faculdade de Direito de Belo Horizonte ...... 1892

\section{Porto Alegre}

Faculdade de Farmácia . .................. 1895

Faculdade de Medicina ...................... 1895

Escola de Engenharia ....................... 1896

Escola de Odontologia .................... 1898

R. Serv. públ., Brasilia, 109 (1) Jan./mar. 1974 
Tratavam-se de unidades com apreciável acersvo de experiências, positivas e negativas, todas indistintamente ignoradas pe los positivistas.

\section{A terceira tentativa}

Os dois fracassos marcaram o País.

Continuávamos sob o peso do ensino barróco, de origem jesuítica, sem ter sido substituido pelo lluminismo apesar dos esforços de Pombal através dos oratorianos, e Barroquismo mais que Barroco propriamente dito, isto é, decadência formalista do do "ratio studíorum", petrificado em estereótipos e preconceitos.

Gilberto Freyre já mostrou como "ler, escrever, contar" foram o martírio dos curumins, mais inclinados à pedagogia franciscana, direta, manual, telúrica. ${ }^{17}$

Foi preciso esperar pela segunda geração republicana para alterar-se o panorama.

Mas acabou sugindo o que, sem exagero, poderíamos chamar de uma plêiade em nossa Cultura, que iniciaria uma nova Revolução Intelectual entre nós, convergindo na instituição da chamada Universidade do Distrito Federal, de efêmera duração, porém talvez a mais original experiência no gênero até hoje, no Brasil.

Ela surgiu em princípios de 1935, funcionando até fins de 1938, sendo fechada como uma das conseqüências do golpe que instalou o Estado Novo, adverso à sua filosofia liberal. Em 1934, Armando de Sales Oliveira, Governador de São Paulo, criara a Universidade do seu Estado, a qual, embora orientada por Fernando de Azevedo, e apesar da potencialidade dos recursos, não percorreu trajetória veloz, compensando com segurança a sua relativa lentidão.

O grande animador da Universidade do Distrito Federal foi Anísio Teixeira, mas este convidou para Reitor o nome mais prestigioso de Afrânio Peixoto. Nela havia cinco escolas : Filosofia e Letras (Diretor: Castro Rebello), Ciências (Diretor: Roberto de Azevedo Marinho), Economia e Direito (Diretor: Hermes Lima), Educação (Diretor : Lourenço Filho), Instituto de Artes (Diretor: Celso Kelly).

Entre outros professores, Gilberto Freyre ali regeu uma das pioneiras cátedras de Sociologia no Brasil (a primeira, aliás, mi- 
nistrada pelo mesmo na antiga Escola Normal de Pernambuco, antes da Revolução de 1930, por proposta do Governador Estácio Coimbra, de quem era íntimo colaborador), Arthur Ramos encarregava-se de Antropologia, ao lado das especialidades de Pedro Calmon, Gastão Cruls, Hélio Gama, Costa Ribeiro, Carlos Werneck, A. Carneiro Leão, Faria Góes Sobrinho, Gustavo Lessa e dos estrangeiros, principalmente francesas, Bréhier, Desfontaines, Perret, Poirier, Lambert, Garric, Antoine Bon e o norte-americano T. Lynn Smith. ${ }^{18}$

Apesar da defesa de Péricles Madureira de Pinho ("Nenhum sectarismo, nenhum partidarismo. A política partidária, essa então não era considerada sequer, na grande obra de Anísio Teixeira. As eleições gerais de 1934 não perturbaram em nada o trabalho"19), a Universidade viu-se fechada no torvelinho que avassalava o Brasil em 1935, 1937, 1938.

A explicação mais clara parece vir de Delgado de Carvatho: "O brilho deste curto prazo de quatro anos foi demasiado $e$ ofuscou um grupo de educadores que açulou governantes incautos contra Anísio e seus colaboradores. O manifesto de Fernando de Azevedo e dos professores signatários havia assustado os títeres da educação nacional ${ }^{n} .20$

Mobilizou-se a inércia, sob justificativa que as mudanças são perigosas sempre.

Fernando de Azevedo, na primeira tentativa organizada de coordenar a pesquisa de História das Ciências no Brasil, fez questão de frisar que "As antigas Escolas de Medicina, como as de Direito, em que, na justa observação de Almeida Júnior, 'a maior parte de seus lentes primavam pelo desamor à renovação científica', essas, não trouxeram no Império como nos primórdios da República, - se excetuarmos Nina Rodrigues e seu grupo na Bahia, - qualquer contribuição importante aos estudos científicos no País. As criações de novos institutos, alguns dos quais vieram com o tempo a adquirir grande projeção no estrangeiro, não obedeciam, também elas, a nenhum plano geral ou a uma nova política de Cultura : eram ou por elas se procuravam respostas aos desafios postos por problemas urgentes..." ${ }^{21}$

Se levarmos em conta que, nas faculdades de Direito. ocorreu igualmente enorme reação contra Tobias Barreto e sua renovação ${ }^{22}$, o quadro estará completo. "Quieta non movere", eis - lema de quase quatrocentos anos de Educação no Brasil, abaR. Serv. públ., Brasília, 109 (1) jan./mar. 1974 
lados episodicamente por espasmos transformadores, abafados no nascedouro, só podendo consumar-se no máximo em alguns setores. $\mathrm{O}$ que equivale a consumirem-se.

Não obstante os percalços, as reformas Francisco Campos e Gustavo Capanema prosseguiram insistindo, ainda que setorialmente, em mudanças na Educação. Dos restos da Universidade do Distrito Federal saiu a Faculdade Nacional de Filosofia, reunindo Filosofia, Ciências, Letras e Educação. Outros professores foram acolhidos em diversas unidades. A Universidade do Brasil fez-se beneficiária, recolhendo os fragmentos espalhados pela resistência.

Com o tempo, não deixaram de dar frutos as lições.

Apareceu a Universidade de Brasília, retomando muitas lições de Anísio Teixeira, e hoje o Brasil tenta aprofundar e renovar inúmeras linhas do Passado, no que ele tem de melhor, com olhos postos no Futuro. As dificuldades e perplexidades apresentam-se inevitáveis, num processo simultaneamente experimental e humanístico, como é a Educação.

\section{NOTAS BIBLIOGRÁFICAS}

1 - Memórias para a História da Academia de São Paulo, Livraria Academia/ Saraiva \& Cia. Editores, 2 vols., São Paulo, 1924.

2 - História da Faculdade de Direito do Recife (11 de agosto de 1827/11 de agosto de 1927), Livraria Francisco Alves, 2 vols., Rio de Janeiro/São Paulo/Belo Horizonte, 1927.

3 - Annaes do Parlamento Brazileiro (Assembléia Constituinte) (1823), Ty. pographia de H. J. Pinto, tomo $2^{\circ}$, Rio de Janeiro, 1879 , sessão em 14 de junho de 1823, p. 63.

4 - Idem, tomo $4 .^{\circ}$, sessão em 27 de agosto de 1823 , pp. 165, 167, 169, 171, 180 e 183.

5 - Ibidem, tomo 5. , sessão em 5 de setembro de 1823 , pp. 42, 50, 51, 54 e 55 .

6 - Vampré, ob. cit., 1. vol., pp. 5-12 e 21.

7 - Apud Beviláqua, ob. cit., $1{ }^{\circ}$ vol., p. 25, referindo-se a texto antes aparecido na Revista Trimestral do Instituto Histórico Brasileiro, tomo XXXVIII, 2." parte, p. 15.

8 - "L'expansion de l'enseignement supérieur au Brésil", in L'expansion de l'enseignement supérior, Association Internationale des Universités, Cachiers 6. Paris, 1960, p. 21. 
9 - Serafim Leite documenta a existência, em Salvador e Olinda, de um estudo elementar, seguido por curso de "Letras Humanas" (Latim, Gre. go, Hebraico) e por curso de "Artes ou Ciências Naturais" ("como então se denominava o curso de Filosofia e abrangia a Lógica, a Física, a Metafísica, a Ética e a Matemática"), coroados pelo curso de "Dialéctica e Teologia" ("Moral", "casuística" evidentemente, e "Especulativa" ou "Dogmática"). "Os primeiros graus de bacharel em Artes datam de 1573 e conferiram-se aos alunos que principiaram o curso em 1572, com o P. Gonçalo Leite. São os primeiros graus acadêmicos que se deram na América Portuguesa; portanto, é uma data a marcar na História da Instrução Luso-Brasileira". "A este primeiro passo seguiram-se outros. $E$ assim, no ano seguinte, deu-se a licenciatura a alguns estudantes externos e a quatro Jesuítas com as costumadas festas; e, em 1578, conferiram-se as primeiras láureas de Mestre em Artes. Foi 0 acto, que revestiu pompa extraordinária, na Igreja do Colégio, com a anuência do Governador Geral e do Bispo. Precedeu disputa pública, recitaram-se epigramas, e houve música de instrumentos e vozes. Receberam aquela dignidade três externos e dois da Companhia, para poderem depois por sua vez dar graus". "Foi um espetáculo europeu". "A imponência deste cortejo e a pompa da imposição das insígnias provocaram indescritível alvorôço na cidade. Tais festas e doutoramenmentos marcam o apogeu dos estudos no Brasil do século XVI". História da Companhia de Jesus no Brasil, tomo I (Século XVI - O Estabelecimento), Livraria Portugália/Civilização Brasileira, Lisboa/Rio de Janeiro, 1938, pp. 72, 75, 77, 96-98 e 102).

10 - "Artigo inicial" in A Universidade (Artigos publicados na Gazetta de Notícias no ano de 94/1882), opúsculo n. 6 do Apostolado Positivista do Brazil, Ric de Janeiro na sede central da Igreja, agosto de 1903, pp. $3,1,2$ e 4 .

.1 - Idem pp. $72.73,5,53,36$ e 37 .

12 - Ainda contra o ensino obrigatório (A propósito do projéto aprezentado ao Conselho Municipal desta cidade, estabelecendo o ensino primário obrigatório), opúsculo n. 262 da Igreja e Apostolado Positivista do Brasil, transcrito da "secção ineditorial do Jornal do Comércio", 26 de junho de 1908, p. 2.

13 - R. Teixeira Mendes, Ainda pelo respeito à plena liberdade de ensino. A propósito do Aviso do Ministro da Justiça ao Presidente do Consetho Superior do Ensino, em 2 de abril corrente, declarando que incumbe ao dito Presidente a fiscalização dos estabelecimentos de ensino su. perior, creados pelos estados ou por particulares, opúsculo $n .^{\circ} 368$ da Igreja e Apostolado Positivista no Brasil, transcrito da "secçắo ineditorial do Jornal do Comércio, 10 de abril de 1914.

14 - R. Teixeira Mendes, Os ensinos de Augusto Comte e a Reforma do Ensino. A propózito da correspondência trocada entre o Sr. Dr. Riva. dávia Correia, Ministro do Interior e o Sr. Dr. Licínio Cardozo, sobre a Reforma do Ensino; correspondência publicada no 'Jornal do Comércio' de 1 de fevereiro corrente (1913) nas 'Várias notícias', opúsculo n.' 373 da Igreja e Apostolado Positivista do Brasil, transcrito da "secção ineditorial do Jornal do Comércio de quarta-feira 5 e quinta-feira 6 de fe-
vereiro de 1913". 
15 - R. Teixeira Mendes, A nova organização do ensino e o Apostolado Pozitivista do Brazil. A propózito do artigo do Dr. Licínio Cardozo, com o título acima, na secçấo editorial do 'Jornal do Comércio' de 8 de feverel. ro corrente (1913), opúsculo $\mathrm{n}$ $^{374}$ da Igreja e Apostolado Positivista do Brasil, transcrito da "secção ineditorial do Jornal do Comércio de terça-feira 11 de fevereiro de 1913.

16 - História do Positivismo no Brasil, vol. 322 da Brasiliana da Cia. Edit. Nacional, São Paulo, 1967.

17 - Casa Grande \& Senzala (Formação da família brasileira sob o regime de economia patriarcal), $1^{\circ}$ tomo, $90^{\circ}$ edição $\left(100^{\circ}\right.$ em língua portuguesa), Livraria José Olympio Edit., Rio de Janeiro, 1958, pp. 200 e 201.

18 - A. Carneiro Leão, "Apóstolo e realizador", in Anísio Teixeira: Pensa. mento e Ação (Por um grupo de professores e educadores brasileiros), Edit. Civilização Brasileira S.A., Rio de Janeiro, 1960, pp. 102 e 103.

19 - "Anísio Teixeira, episódios de sua vida e de sua luta", in idem, pp. 176 e 177.

20 - "Anísio, vulcão de idéias", in ibidem, p. 222.

21 - "Introdução", in As Ciências no Brasil (Obra organizada e publicada sob a direção e com uma Introdução de Fernando de Azevedo), vol. I, sob os auspícios da Instituição Larragoiti e por iniciativa de seu Diretor, Prof. Leonídio Ribeiro, Ediç̧̃es Melhoramentos, São Paulo, s.d., pp. 32 e 33.

22 - Já o demonstrei, com inúmeros documentos, em Da Escola do Recife ao Código Civil, Organização Simões Edit., Rio de Janeiro/GB., s.d. 
